\title{
Combined usage of estrogen and melatonin restores bladder contractility and reduces kidney and bladder damage in ovariectomized and pinealectomized rats
}

\author{
Tasdemir S ${ }^{1}$, Tasdemir $C^{2}$, Vardi $N^{3}$, Parlakpinar $\mathrm{H}^{1}$, Aglamis $\mathrm{E}^{4}$, Ates $\mathrm{B}^{5}$, Sagir $\mathrm{M}^{1}, \mathrm{Kurt}^{1}$, Acet $\mathrm{A}^{1}$
}

Department of Pharmacology, Inonu University, Medical Faculty, Malatya, Turkey. sedamd23@gmail.com

\begin{abstract}
Objective: The incidence of urinary bladder disturbances and renal structural changes and functional decline are found to increase with age.

Methods: We investigated the effect of melatonin treatment in addition to estrogen replacement therapy in pinealectomized $(\mathrm{Px})$ and ovariectomized (Ovx) rats. 56 female Wistar rats were divided into seven groups, each containing eight animals: Sham, $(\mathrm{Ovx}),(\mathrm{Px}), \mathrm{Px}+\mathrm{Ovx}, \mathrm{Px}+\mathrm{Ovx}$ receiving estrogen $(\mathrm{Px}+\mathrm{Ovx}+\mathrm{E}), \mathrm{Px}+\mathrm{Ovx}$ receiving melatonin $(\mathrm{Px}+\mathrm{Ovx}+\mathrm{M})$ and $\mathrm{Px}+\mathrm{Ovx}$ estrogen and melatonin supplemented (Px+Ovx+EM) group (EM group). We evaluated reduced glutathione (GSH) levels and malondialdehyde (MDA) levels. The mean collagen fiber (CF)/smooth muscle (SM) ratio in the bladder wall and structure of the kidney were examined histolologically. We aleso recorded response of the bladder contractility to acetylcholine (Ach).

Results: Px and Ovx groups showed statistically significant reductions of antioxidant defenses, impaired Achevoked contraction, histological changes compared with the control group. Also, these changes were prominent in Px+Ovx group compared with all other groups. Both estrogen and melatonin reversed these changes however best restoration was observed in the EM group.

Conclusions: Px performed in addition to Ovx led to a distinct increase in oxidative damage in bladder and renal tissue and deteriorate of the detrussor function. Either estradiol or melatonin replacement alone or in combination prevents significant alterations of tissue histology and bladder contractility following Ovx and Px. Thus, combination treatment appears to be the best method to restore both contractility and histomorphology of bladder and kidney tissues after Ovx and Px (Tab. 3, Fig. 4, Ref. 44). Text in PDF www.elis.sk. Key words: pinealectomy, ovariectomy, estrogen, melatonin, bladder, kidney.
\end{abstract}

Menopausal period induces some hormonal changes in the female organism. These alterations are responsible for many illnesses such as climacteric symptoms, urine incontinence, connective tissue lesions, postmenopausal osteopenia and osteoporosis. All these changes negatively influence the quality of life of women (1). Also, in elderly people, the pineal gland wrinkles and loses its melatonin synthesis ability. This situation may cause damage in the kidney which is one of the better perfused organs. The mechanism(s) underlying renal failure during aging is thought to be sophisticated and related to hypoperfusion, loss of pulsatile perfusion, accumulation of free radicals, and a systemic inflammatory response (2). As a result, both, estrogen deficiency and decrease in the synthesis of melatonin are observed in menopausal period.

${ }^{1}$ Department of Pharmacology, Inonu University, Medical Faculty, Malatya, Turkey, ${ }^{2}$ Department of Urology, Inonu University, Medical Faculty, Malatya, Turkey, ${ }^{3}$ Department of Histology, Inonu University, Medical Faculty, Malatya, Turkey, ${ }^{4}$ Department of Urology, Elazig Training and Research Hospital, Elazig, Turkey, and ${ }^{5}$ Department of Chemistry, Faculty of Science and Art, Inonu University, Malatya, Turkey

Address for correspondence: S. Tasdemir, Inonu University, Medical Faculty, Pharmacology Department, 44280, Malatya, Turkey. Phone: +9004223410660-1240, Fax: +9004223410036

Acknowledgement: This project was supported by a Grant from Scientific Research Fund of Inonu University, Turkey.
Urinary bladder disturbances are frequent in the elderly population who often complain of urgency, frequency, nocturia, and incontinence however the responsible mechanisms are poorly understood (3). Human and animal studies have shown that estrogen receptors are located throughout the bladder and urethra (4). Thus, the urogenital tract is sensitive to the effect of estrogenduring adult life. Epidemiological studies have implicated estrogen deficiency plays a major role in bladder dysfunctions which include urethral and pelvic floor muscle weakness, urgency, frequency and underactive detrussor in the postmenopausal women (5). Also, recent studies suggested that melatonin could restore the age-induced changes in bladder neuromuscular function (6). It has been reported that melatonin restores the contractile response to cholinergic stimulation in the inflamed bladder (3).

In the free radical theory of aging, it is suggested that accumulated free radical damage may be responsible for the degenerative process during aging. It is known that there is a reduction of serum melatonin wit aging. The age-related loss of renal parenchyma approximates $10 \%$ per decade of increasing age (7). This loss is accompanied by a decrease in renal plasma flow (8-11) and tubular dysfunction (12). Also, the autopsy studies in apparently healthy aging individuals show that aging lead to an increase in globally sclerotic glomeruli, a progressive loss of glomeruli (13). According to our knowledge, there is no previous study revealing 
effect of estrogen and melatonin on the renal structural changes in aging animals.

The aim of the present study was to expose rats to one aspect of the ageing process via surgical pinealectomy $(\mathrm{Px})$ and ovariectomy (Ovx) and evaluate the effect of melatonin and estrogen replacement on detrusor myogenic contractile responses in Ovx and Px rat model through the identification of histochemical alterations of the bladder and kidney tissue.

\section{Material and methods}

\section{Experimental groups}

Fifty-six female Wistar rats weighing 150-200 g were kept at a constant temperature $\left(21 \pm 2{ }^{\circ} \mathrm{C}\right)$ and humidity $(60 \pm 5 \%)$ in acontrolled room in which a $12: 12 \mathrm{~h}$ light-dark cycle was maintained.

The rats were divided into seven groups of eight animals each by simple randomization methods as follows: 1) Sham-operated 2) $\mathrm{Px}$ 3) Bilateral Ovx 4) $\mathrm{Ovx}+\mathrm{Px}$ 5) $\mathrm{Ovx}+\mathrm{Px}+$ Melatonin (M) 6) $\mathrm{Ovx}+\mathrm{Px}+$ estrogen (E) 7) $\mathrm{Ovx}+\mathrm{Px}+\mathrm{EM}$. Rats with $\mathrm{Px}, \mathrm{Ovx}$ or $\mathrm{Ovx}+\mathrm{Px}$ were housed for 5 months before the beginning of treatment. Melatonin (Sigma Chemical Co., St Louis, MO, USA) was dissolved in ethanol and further diluted in saline (vehicle) $(0.09 \%$ $\mathrm{NaCl}, \mathrm{w} / \mathrm{v}$ ) to give a final concentration of $1 \%$. Melatonin-treated animals were injected with $5 \mathrm{mg} / \mathrm{kg}$ melatonin (i.p.) for 28 days. All injections were administered at 17:00 h. Estrogen-treated animals received subcutaneous injections of $250 \mu \mathrm{g} / \mathrm{kg} \beta$-estradiol 17-cypionate (Sigma) in corn oil once a week for 4 weeks. Animals from sham-operated and $\mathrm{Ovx}+\mathrm{Px}$ group received an equal volume $(0.5 \mathrm{~mL} / \mathrm{kg})$ of vehicle solution.

The experiment was performed in accordance with the Guidelines for Animal Research from the National Institute of Health and was approved by the Committee on Animal Research at Inonu University, Malatya.

For experimental Px and Ovx in the same season, the rats were preoperatively anesthetized with a mixture of ketamine hydrochloride $(75 \mathrm{mg} / \mathrm{kg})$ and xylazine hydrochloride $(8 \mathrm{mg} / \mathrm{kg})$ intraperitoneally (i.p.). According to anatomic localization of pineal gland and ovaries, the skin was shaved with electric clippers and prepared with povidone-iodine (Poviiodeks;Kim-Pa Ilac Lab. Tic. Ltd. Sti., Istanbul, Turkey). During the surgical procedure asepsis was maintained with a local sterile environment.

\section{Pinealectomy}

Pinealectomy was performed as described by Hoffman and Reiter (14). The skin on the top of the head was cut to expose the skull. The animal was fastened to the dissection table; an incision was made in the skin and the subcutaneous tissue, bringing the lambda into view. The skullcap was opened with the aid of a micromotor, bringing the cerebral hemispheres and the superior sagittal sinus into view. The pineal gland, located under the venous sinus, was removed in one piece using forceps. Next, the bone fragment was returned to its place and the surgical layers were sutured. After surgery, the animals received a single dose of prophylactic antibiotic. The procedure was completed within $15 \mathrm{~min}$. Pinealectomy was confirmed by the histological evaluation of the gland for each animal. Rats in the sham-operated group underwent similar surgical procedures without the removal of the pineal gland.

\section{Ovariectomy}

It was performed bilateraly under the anesthesia $4 \mathrm{~cm}$ midline laparotomy was made through the flank skin of the rat, and the ovaries and ovarian fat were removed. Ovaries were isolated by ligation of the most proximal portion of the oviduct before removal (15). Immediately after surgery, $5 \mathrm{mg} / \mathrm{kg}$ of carprofen was injected subcutaneously for analgesia.

\section{Preparation of rat urinary bladder strips}

After the last injection the bladders were obtained from all rats. Each bladder was divided into 2 pieces. The first sample was used for histopathological examination. We immediately placed the second sample in an isolated organ bath filled with Krebs-Henseleit solution containing (in $\mathrm{mmol} / \mathrm{L}$ ): $\mathrm{NaCl} \mathrm{118,} \mathrm{KCl} 4.8, \mathrm{CaCl}_{2} 2.5$, $\mathrm{KH}_{2} \mathrm{PO}_{4} 1.2, \mathrm{MgSO}_{4} .7 \mathrm{H}_{2} \mathrm{O} 1.2, \mathrm{NaHCO}_{3} 25$, and glucose $10 ; 37$ ${ }^{\circ} \mathrm{C}, \mathrm{pH} 7.4$ ) and continuously bubbled with a mixture of $95 \% \mathrm{O}_{2}$ and $5 \% \mathrm{CO}_{2}$. The lower end of the strip was fixed to a metal hook and the upper end attached to an isometric force-displacement transducer (BIOPAC Systems, Inc). All strips $(2 \times 10 \mathrm{~mm})$ were allowed to equilibrate under a resting tension of $1 \mathrm{~g}$ for $60 \mathrm{~min}$ (the bath fluid was changed every 15 min with fresh Krebs solution). After this period, all preparations were contracted with $10 \mathrm{mM}$ acetylcholine (ACh). We quantified the contractility patterns in all groups by changes in mean amplitude (g).

\section{Biochemical determination}

The tissue samples were stored at $-80{ }^{\circ} \mathrm{C}$ for the determination of malondialdehyde (MDA) and total glutathione (GSH). The tissue specimens were homogenized (PCV Kinematica Status Homogenizator) in ice-cold phosphate buffered saline ( $\mathrm{pH}$ 7.4). The homogenate was sonified with an ultrasonifier (Bronson sonifier 450) by three cycles (20-s sonications and 40-s pause on ice). The homogenate was centrifuged $\left(15000 \mathrm{~g}, 10 \mathrm{~min}, 4{ }^{\circ} \mathrm{C}\right)$, and cell-free supernatant was subjected to enzyme assay immediately.

The level of GSH was determinedusing the method of Theodorus et al. with some modifications (16). The reaction mixture contained $50 \mathrm{mM}$ sodium phosphate, $1 \mathrm{mM}$ EDTA, $0.5 \mathrm{mM}$ DTNB, $0.2 \mathrm{mM}$ $\mathrm{NADPH}$, and $0.5 \mathrm{U} / \mathrm{mL}$ of glutathione reductase. Homogenate (10 1L) was added to initiate the reaction but was omitted for control. The formation of 5-thio-2-nitrobenzoate is followed spectrophotometrically at $412 \mathrm{~nm}$. The amount of GSH in the extract was determined as nmol/mg protein utilizing a commercial GSH as the standard.

The analysis of MDA was carried out as described by Buege et al (17) with a minor modification. The reaction mixture was prepared by adding $250 \mathrm{~mL}$ homogenate into $2 \mathrm{~mL}$ reaction solution (15\% trichloroacetic acid: $0.375 \%$ thiobarbituric acid: 0.25 $\mathrm{N} \mathrm{HCl}, 1: 1: 1, \mathrm{w} / \mathrm{v})$ and heated at $100{ }^{\circ} \mathrm{C}$ for $15 \mathrm{~min}$. The mixture was cooled to room temperature, centrifuged (10000 $\mathrm{g}$ for $10 \mathrm{~min})$, and the absorbance of the supernatant was recorded at $532 \mathrm{~nm}$. 1,1,3,3-Tetramethoxypropane was used as MDA standard. MDA results were expressed as nmol per mg protein in the homogenate. 


\section{Histological evaluations}

The tissues were fixed in $10 \%$ formalin for approximately 24 $\mathrm{h}$ and embedded in paraffin blocks. The tissue blocks were cut into $4 \mu \mathrm{m}$ sections. The sections were stained with hematoxylin-eosin for urinary bladder epithelium and general structure of the kidney. Masson's trichrome stain was used for demonstrating the collagen and muscle in the urinary bladder. The collagen was stained green and muscle was stained as red with Masson's trichrome. The areas that were stained red and green were measured using Leica Q Win software image analysis system (Leica Micros Imaging Solutions Ltd, Cambridge, UK) on slides. Morphometric assays were made in ten different fields for each section. The average area for $\mathrm{CF}$ and $\mathrm{SM}$ and $\mathrm{CF} / \mathrm{SM}$ ratio were calculated for each group.

The kidneys were examined for the presence of tubular injury and interstitial changes by an experienced observer unaware of the animal treatment groups. The tubular injury was defined as tubular desquamation and tubular epithelial cell swelling. The following semiquantitative score was used: score $0=$ no tubular injury, score $1=<10 \%$ of tubules were injured, score $2=10-25 \%$ of the tubules were injured, score $3=25-50 \%$ of the tubules were injured, score $4=50-75 \%$ tubules injured and score $5=>75 \%$ of tubules were injured. The tubulointerstitial area was evaluated as inflammatory cell infiltration, haemorrhagia and congestion. The interstitial changes were graded from 0 to $4(0=$ no changes; $1=$ changes affecting less than $25 \%$ of the samples; $2=$ changes affecting $25-50 \%$ of the samples; $3=$ changes affecting 50-75 $\%$ of the samples; $4=$ changes affecting more than $75 \%$ of the

Tab. 1. Mean urinary bladder contractile responses of the groups (Mean values $\pm \mathrm{SE}$ ).

\begin{tabular}{lc}
\hline Groups & Mean \pm SE \\
\hline Sham & $3.15 \pm 0.12$ \\
Px & $2.14 \pm 0.18^{\mathrm{a}, \mathrm{b}}$ \\
Ovx & $1.95 \pm 0.14^{\mathrm{a}, \mathrm{b}}$ \\
Px-Ovx & $1.46 \pm 0.08^{\mathrm{a}}$ \\
Px-Ovx $+\mathrm{E}$ & $1.89 \pm 0.12^{\mathrm{a}, \mathrm{c}}$ \\
Px-Ovx $+\mathrm{M}$ & $1.95 \pm 0.13^{\mathrm{a}, \mathrm{c}}$ \\
Px-Ovx + EM & $2.52 \pm 0.08^{\mathrm{a}, \mathrm{c}, \mathrm{d}}$ \\
\hline
\end{tabular}

a Mean value was significantly decreased compared with that the sham group $(\mathrm{p}<0.05)$, ${ }^{b}$ Mean value was significantly decreased compared with Px and Ovx groups $(\mathrm{p}<0.05)$, ${ }^{c}$ Mean value was significantly increased compared with the Px-Ovx group $(\mathrm{p}<0.05)$, ${ }^{d}$ Mean value was significantly increased compared with the Px-Ovx $+\mathrm{E}$ and $\mathrm{Px}-$ Ovx $+\mathrm{M}$ groups $(\mathrm{p}<0.05)$.

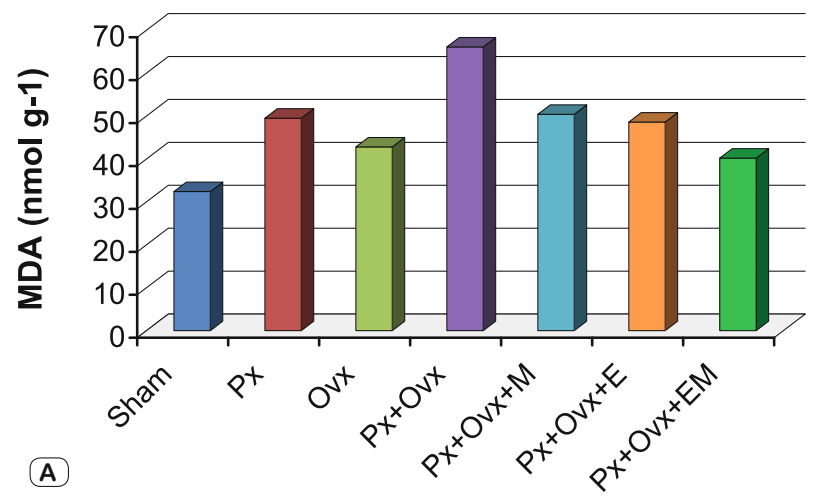

samples). For each specimen 10 microscopic fields were analyzed under a 20X objective per animals (18).

\section{Statistical analysis}

The results are given as mean \pm standard error (S.E) in the text. Normality of the distribution was confirmed using the Kolmogorov-Smirnov Z-test. The homogeneity of variance assumption was examined using Levene's test. Where differences among the groups were detected, group means were compared using the Mann-Whitney U test. Values of $\mathrm{p}<0.05$ were considered significant. The differences were considered significant when $P<0.05$. Statistical analyses were performed using The Statistical Package for Social Sciences (SPSS, Chicago, IL, USA) (Ver.17.0).

\section{Results}

\section{Bladder contractile responses}

Table 1 shows the mean amplitudes of contractility measurements in all groups in response to $100 \mu \mathrm{mol} / \mathrm{l} \mathrm{Ach}$. The isolated bladder strips revealed significantly decreased bladder contractility in the groups of Px ,Ovx, Px+Ovx compared with the sham-operated rats $(\mathrm{p}<0.05)$. This finding was prominent in $\mathrm{Px}+\mathrm{Ovx}$ group. Also, both exogenous melatonin and estrogen treatments tended to reverse this effect $(p<0.05)$. We further evaluated the combined usage of estrogen and melatonin on ACh-induced contractions of bladder strips. The combination of melatonin and estrogen treatment was more efficient on bladder contractile response than single application of either estrogen or melatonin.

\section{Biochemical results}

The mean level of MDA, which is a major degradation product of lipid peroxidation, in bladder and kidney samples showed a marked increase following Px and Ovx compared with the sham group $(\mathrm{p}<0.005)$. It was seen that the highest levels of MDA were in $\mathrm{Px}+\mathrm{Ovx}$ groups $(\mathrm{p}<0.005)$. On the other hand, estrogen and melatonin treatment in the $\mathrm{Px}+\mathrm{Ovx}$ group reduced MDA levels $(p<0.005)$. The combination treatment was more efficient in reducing MDA levels than a single administration (Figs 1A, 1B).

The GSH values of all groups are shown in Figures $2 \mathrm{~A}$ and 2B. Px and Ovx was accompanied by a significant decrease in

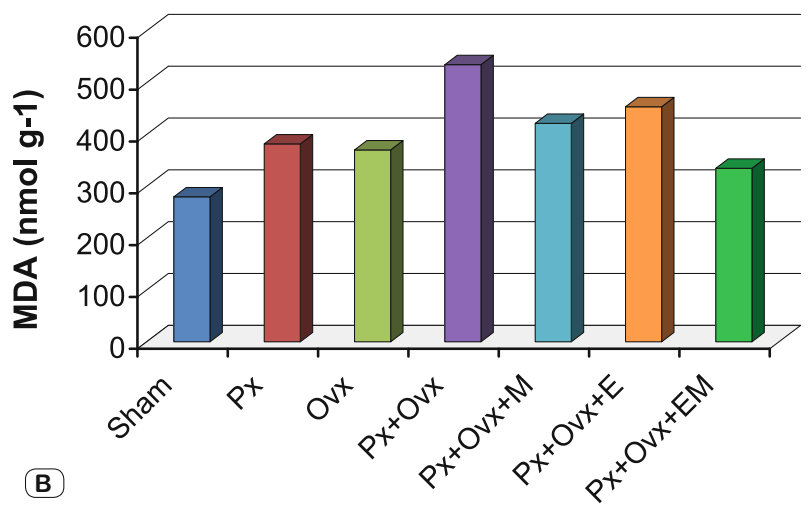

Fig. 1. MDA level in bladder (A) and kidney (B) tissues. 

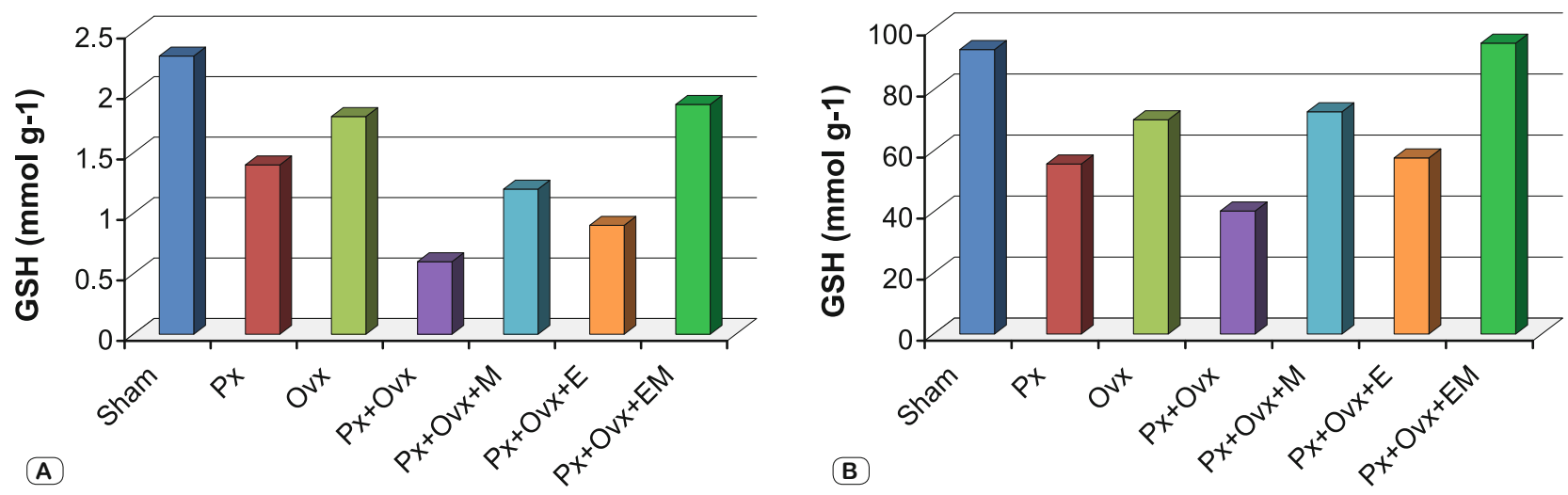

Fig. 2. Bladder (A) and kidney (B) GSH levels in all groups.

GSH levels, whereas, melatonin and estrogen administration significantly reduced these values $(\mathrm{p}<0.005)$. It was seen that the highest levels were found in $\mathrm{Px}+\mathrm{Ovx}+\mathrm{M}+\mathrm{E}$ group and lowest levels were found in $\mathrm{Px}+\mathrm{Ovx}(\mathrm{p}<0.005)$.

\section{Histological results}

\section{Bladder}

Mean collagen fiber $(\mathrm{CF}) /$ smooth muscle $(\mathrm{SM})$ ratio ranged from low (control, $0.98 \pm 0.1)$ to moderate $(\mathrm{Px}-\mathrm{Ovx}+\mathrm{M}, 1.04 \pm$ 0.1 and $\mathrm{Px}-\mathrm{Ovx}+\mathrm{EM}, 1.04 \pm 0.1)$ and to high $(\mathrm{Px}, 1.15 \pm 0.1$; Ovx, $1.15 \pm 0.1 ; \mathrm{Px}-\mathrm{Ovx}+\mathrm{E}, 1.15 \pm 0.2$ and, Px-Ovx, $1.21 \pm 0.0)$. The ratio for the Px-Ovx group was higher than in the sham group ( $\mathrm{p}$ $=0.009$ ). On the other hand, the CF/SM ratio was similar to each other in sham and Px-Ovx+EM groups. There was no significant difference between the ratios of the Px-Ovx group and the PxOvx + E group $(p>0.05)$. Also there was no significant difference between the ratios of the group $\mathrm{Px}-\mathrm{Ovx}+\mathrm{M}$ and $\mathrm{Px}-\mathrm{Ovx}+\mathrm{EM}$ group $(p>0.05)$. The mean collagen fiber, smooth muscle and CF/SM ratio are given in Table 2 .

The control group exhibited normal stratified transitional urinary bladder epithelium with H\&E staining method (Fig. 3A). In the Px, Ovx and $\mathrm{Px}-\mathrm{Ovx}+\mathrm{E}$ groups, the number of layers of stratified transitional urinary bladder epithelium was decreased (Figs 3B, C and D). There was also desquamation of the lining of epithelial cells and loss of urothelial cells in Px-Ovx group. Ex-

Tab. 2. Mean CF, SM, and CF/ SM values of the groups (Mean values $\pm \mathrm{SE})$.

\begin{tabular}{lccc}
\hline Groups & CF & SM & CF/SM ratio \\
\hline Sham & $126.7 \pm 23.5$ & $129.3 \pm 36$ & $0.98 \pm 0.1$ \\
Px & $165.3 \pm 13$ & $142.6 \pm 16.4$ & $1.15 \pm 0.1^{\mathrm{a}}$ \\
Ovx & $156.3 \pm 3.6$ & $137.1 \pm 20.6$ & $1.15 \pm 0.1$ \\
Px-Ovx & $163.3 \pm 14.1$ & $133.3 \pm 13.8$ & $1.21 \pm 0.0^{\mathrm{a}}$ \\
Px-Ovx $+\mathrm{E}$ & $156.0 \pm 34.0$ & $134.8 \pm 21$ & $1.15 \pm 0.2^{\mathrm{d}}$ \\
Px-Ovx $+\mathrm{M}$ & $137.8 \pm 4.8$ & $132.6 \pm 6.8$ & $1.04 \pm 0.1^{\mathrm{c}}$ \\
Px-Ovx + EM & $117.4 \pm 18.7$ & $112.2 \pm 2$ & $1.04 \pm 0.1^{\mathrm{b}, \mathrm{c}}$ \\
\hline
\end{tabular}

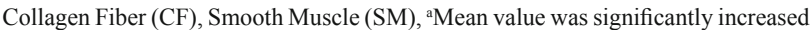
compared with that of the control group $(\mathrm{p}<0.05)$, ${ }^{\mathrm{b}} \mathrm{Mean}$ value was significantly decreased compared with that of the Px-Ovx group $(\mathrm{p}<0.05)$, ${ }^{\mathrm{C}} \mathrm{No}$ significant when compared with control group ( $p>0.05),{ }^{\mathrm{d}}$ No significant when compared with group, Px-Ovx ( $>00.05)$.
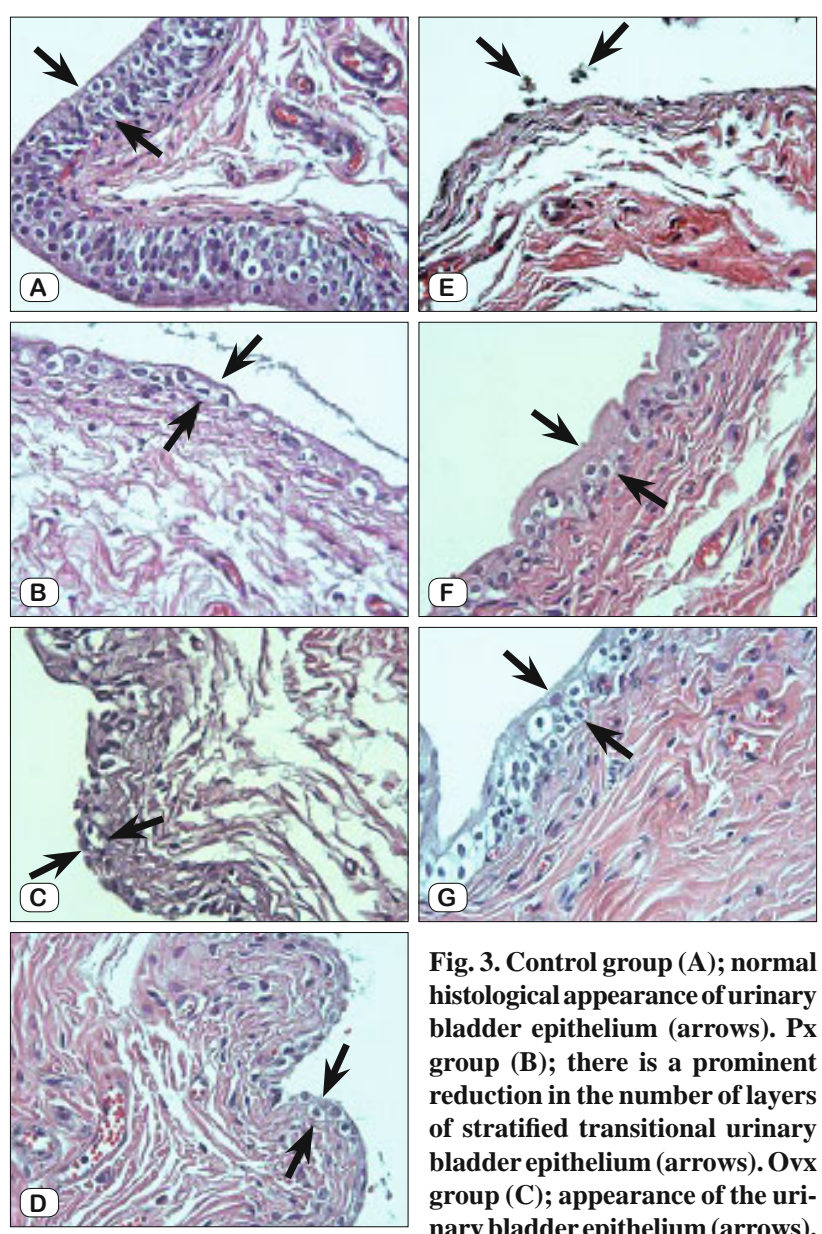

Fig. 3. Control group (A); normal histological appearance of urinary bladder epithelium (arrows). Px group (B); there is a prominent reduction in the number of layers of stratified transitional urinary bladder epithelium (arrows). Ovx group (C); appearance of the urinary bladder epithelium (arrows). Px-Ovx+E group (D); view of epithelium (arrows) is similar to Ovx group. Px-Ovx group (E); loss of luminal surface epitelium is evident. Note the shedding of epithelial cells into the urinary bladder lumen (arrows). PxOvx + M group (F); The histological aspect of luminal surface epitelium is more regular and intact than Px-Ovx group. Px-Ovx+EM (G); group; appearance of epithelium resembling $\mathrm{Px}-\mathrm{OvX}+\mathrm{M}$ group, H-EX40.

foliated urothelial cells were detected in the lumen of the urinary bladder in this group (Fig. 3E). In the Px-Ovx+M and Px-Ovx+EM groups, although the urothelium preserved almost its normal appearance, some areas showed local epithelial desquamation and 


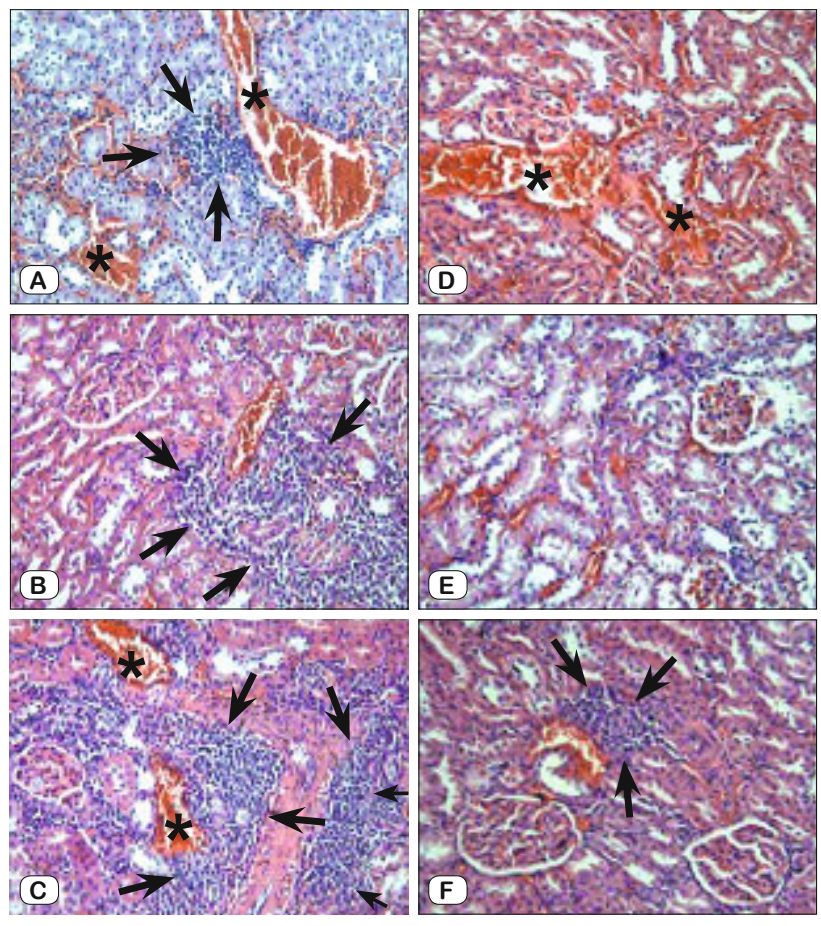

Fig. 4. Px group (A); interstitial congestion (*) and inflammatory cell infiltration (arrows). Ovx group (B); inflammatory cell infiltration is localized. Px-Ovx group (C);

Tubulointerstitial area shows marked congestion (*) and inflammatory cell infiltration (arrows). Px-Ovx+E group (D); there is a prominent reduction in renal damage compared to $\mathrm{Px}-\mathrm{Ovx}$ group. Px-Ovx+M group (E); the histological aspect is similar to $\mathrm{Px}-\mathrm{Ovx}+\mathrm{E}$ group. Px$O v x+E M$ group (F); inflammatory cell infiltration and congestion is limited. Slight tubular desquamation is present in all groups. H-EX20.

epithelial thinning, however, they were not as extensive as in the Px-Ovx group (Figs 3F and G).

\section{Kidney}

The sham group revealed normal kidney parenchyma (Figure not shown). The morphological damage was marked in tubulointerstitial area rather than tubules in the treatment groups. Degenerative changes in the interstitial area were moderate in the Px and Ovx groups. The histological findings of these two groups were close to each other (Figs 4A and 4B). The Px-Ovx group showed

Tab. 3. The comparison of severity of renal damage among groups. (Mean values $\pm \mathrm{SE}$ ).

\begin{tabular}{lcc}
\hline Groups & TD & TID \\
\hline Sham & $0.3 \pm 0.5$ & $0.1 \pm 0.4$ \\
Px & $0.83 \pm 0.4$ & $2.3 \pm 0.5^{\mathrm{a}}$ \\
Ovx & $1.16 \pm 0.4$ & $2.5 \pm 0.5^{\mathrm{a}}$ \\
Px-Ovx & $1.0 \pm 0.6$ & $4.0 \pm 0.6^{\mathrm{a}}$ \\
Px-Ovx $+\mathrm{E}$ & $1.5 \pm 0.5$ & $1.3 \pm 0.5^{\mathrm{b}, \mathrm{d}}$ \\
Px-Ovx $+\mathrm{M}$ & $1.16 \pm 0.4$ & $1.16 \pm 0.4^{\mathrm{b}, \mathrm{d}}$ \\
Px-Ovx + EM & $0.3 \pm 0.5$ & $1.16 \pm 0.4^{\mathrm{b}}$
\end{tabular}

TD - Tubular Damage; TID - Tubulointerstitial Damage, ${ }^{a}$ Mean value was significantly increased compared with that of the control group $(p=0.002)$, ${ }^{b}$ Mean value was significantly decreased compared with that of the Px-Ovx group $(\mathrm{p}<0.05),{ }^{\mathrm{d}}$ Not significant when compared with group Px-Ovx+EM ( $p>0.05)$. extreme interstitial damage such as interstitial congestion, hemorrhage and inflammatory cell infiltration (Fig. 4C). The damage in the interstitial area was observed as decreased in Px-Ovx+E and Px$\mathrm{Ovx}+\mathrm{M}$ groups and it was not as extensive as in the Px-Ovx group (Figs 4D and 4E). Inflammatory cell infiltration and congestion were limited in these groups. Px-Ovx+EM group was also similar to Px-Ovx+M group (Fig. 4F). The most obvious tubulointerstitial damage occurred in the Px-Ovx group $(4.0 \pm 0.6)$ followed by the Px and Ovx $(2.5 \pm 0.5$ and $2.3 \pm 0.5)$ then Px-Ovx $+E$, $(1.3 \pm 0.5) \mathrm{Px}-$ $\mathrm{Ovx}+\mathrm{M}(1.16 \pm 0.4)$ and lastly in Px-Ovx+EM (1.16 \pm 04$)$ groups. Slight tubular desquamation was present in all groups (Tab. 3).

\section{Discussion}

Ovx rats have been used as a model of menopause induced estrogen deficiency in humans (3). Iit has long been documented that both ratios of calcified pineal gland and the density of pineal calcification increased progressively with aging. Decreases of the total antioxidant capacity of human serum with age nearly correlate with its melatonin concentration (19). Advancing age leads to some changes in the structure and functions of the bladder and kidney tissue (20). The results of the present study indicate that Px and Ovx increase MDA levels whereas they decrease the GSH levels and urinary bladder contractile response. Also, a significant structural damage in the bladder and kidney tissue was determined. These findings are most pronounced in Ovx $+\mathrm{Px}$ group. Both estrogen and melatonin treatment reduced the morphological damage and repaired the detrusor function. However, the combined therapy of estrogen and melatonin was significantly more effective than when estrogen or melatonon were applied alone.

Decreases in estrogen concentration associated with menopause have been considered as a factor responsible for increasing the urinary incontinence prevalence in aging women (21). Sex hormones are known to have an important influence on the function of the lower urinary tract throughout adult life (5). Thus, hormone replacement is used in postmenopausal women with lower urinary tract dysfunction (22). Several factors such as neuronal innervation, structure of organs and the contractile response of the smooth muscle elements may affect the bladder function. These factors are closely correlated to each other, and a change in one factor can cause important adaptive changes in the other two. Thus, hormone replacement therapy can considerably affect the bladder function by changing innervations and vascular density and distribution, receptor density and distribution, smooth muscle size and number, and connective tissue density and distribution (23-25). There are considerable contradictory data on the effect of estrogen administration on bladder function and structure. Rehfuss et al (26) reported that the low estrogen level induced decreased bladder mass, smooth muscle content, contraction, blood flow and increased free radical damage. Also, previous studies suggested that Ovx can cause a decreased of blood flow around the bladder neck and urethra, mucosal and smooth muscle atrophy, increased collagen synthesis and distribution, and decreased contractility. Estrogen replacement reduced the effects of Ovx and resulted in smooth muscle hypertrophy and enhanced contractility (27). 
Also it has been reported that estrogen mediates angiogenesis accounting for the increased vascular density and increased blood flow. The effects may be mediated through tissue energy supplies (5). On the other hand data from the randomized, double-blind, placebo-controlled trials clearly show that hormonal therapy neither improves continence nor prevents the development of incontinence in continent individuals. Thus, the authors have not reached a consensus about hormonal therapy for the treatment of incontinence $(28,29)$. In our study, we determined that Ovx caused oxidative damage in rats, therefore the level of MDA, a product of lipid peroxidation, is generated as a result of the toxic effects of active oxygen radicals. The levels of GSH which have roles as antioxidants in the organism were decreased significantly after removing estrogen from the body. This parameter increased more as a consequence of Ovx with Px. The results of our study demonstrate that Ovx and $\mathrm{Px}$ in rats increased the $\mathrm{CF} / \mathrm{SM}$ ratio in the bladder wall $(\mathrm{p}<0.05)$. Both estrogen and melatonin treatment decreased this ratio. However melatonin was more effective than estrogen. In vitro studies show that aging affects both the myogenic responses to neurotransmitters and $\mathrm{Ca}^{2+}$ sensitization mechanisms in smooth muscle $(30,31)$. However, considerable contradictory data are still present on the effect of estrogen administration on bladder function and structure. There is a significant variation in the reported results. Some studies show age-dependent raises (32, 33) or reduction in ACh-induced responses (34), whereas others report no changes in carbachol stimulated contraction $(35,36)$. Our data showed that Ovx impairs Ach-evoked contractile response and estrogen treatment recovered the detrusor contraction by its effect on the oxidative stress and CF $\backslash \mathrm{SM}$ ratio.

Melatonin, the main secretory product of the pineal gland, is known to be a potent free radical scavenger and anti-oxidant. The decrease in total antioxidant capacity of human serum with age nearly correlates with its melatonin concentration (19). The incidence of urinary bladder disturbances increases with age. Gomez-Pinilla et al showed that a reduction in $\mathrm{Ca}^{2+}$ sensitization mechanisms which correlates with increased oxidative stress was proposed as a causal factor. Also, they suggested that the melatonin treatment restored the contractile response of bladder smooth muscle through an increase $\mathrm{Ca}^{2+}$ sensitivity and normalized oxidative stress parameters (3). Onur et al (37) determined that melatonin restored bladder contractility in rabbits with partial outlet obstruction by antioxidant effect. In the present study, we demonstrated that Px induced a reduction of antioxidant defenses including GSH in bladder and kidney tissue. Px was more efficient than Ovx on MDA and GSH levels (especially in kidney). In addition, Pedro J et al (38) reported that the antioxidant properties of melatonin could ameliorate the alterations of bladder neuromuscular function associated with age. Also, Yasmir Quiroz et al (39) reported that melatonin treatment reduced oxidative stress and inflammation, decreased the abundance and expression of collagen, transforming growth factor- $\beta$, and $\alpha$-smooth muscle actin, and prevented functional and structural deterioration in the remnant kidney. The results of the present study demonstrated that Px induced a decrease in contractile responses to nerve stimulation and the administration of melatonin attenuates deterioration of detrusor function and structure.
Aging is associated with renal structural changes and functional decline (40). The investigators discovered an age-related nephrosclerosis (41) and a gradual loss of nephron number with aging (42). Nyengaard and Bendtsen (43) showed that the "senile" kidney was characterized by nephron and kidney shrinkage, an increase in globally sclerotic glomeruli. There are a great number of different theories of primarily disease-independent renal aging. Recent evidence has been provided that various pathophysiologic pressures such as oxidative stress and mitochondrial injury can be induced to aging kidney. It is suggested that enalapril and losartan treatments reduce age-associated renal damage by attenuating the age associated increase in mitochondrial oxidant production (44). In our study, we explored whether a reduction of melatonin and estrogen levels in the circulation played an important role in the damage to the kidney resulting from aging. We documented that renal MDA levels in Px+Ovx, Px, Ovx rats were higher than in control animals. Morpholological changes including tubular desquamation and tubular epithelial cell swelling, tubulointerstitial haemorrhagia and congestion were clearly observed in the kidney of $\mathrm{Px}+\mathrm{Ovx}$ rats. However, appearance of glomeruli was normal. The most remarkable repair was in the combination treatment group.

\section{Conclusion}

Recent studies suggested that both Ovx and Px have an effect on oxidant and antioxidant systems in bladder and kidney tissues. It is also well known that estrogen deficiency has an important role on the detrusor function and bladder structure. Thus, in the current study we mainly focused on the effects of melatonin treatment in addition to estrogen replacement therapy in Px and Ovx rats. In conclusion, this study demonstrated that Px deteriorated the bladder function and structure by increasing oxidative stress in Ovx rats. Also, we found a significant impairment in the kidney structure. Estrogen or melatonin supplementation in the Ovx-Px rats reduced the damage by activating the antioxidant systems. However, the combined use of melatonin and estrogen was more effective than single treatment. Finally, the protective effects of both melatonin and estrogen treatments on the renal and bladder structure and functions should also be further investigated.

\section{References}

1. Pertynski T, Stachowiak G. Menopause - facts and controversies. Endokrynol Pol.2006; 57 (5): 525-534.

2. Parlakpinar H, Acet A, Gul M et al. Protective effects of melatonin on renal failure in pinealectomized rats. Int J Urol.2007; 14 (8): 743-748.

3. Gomez-Pinilla PJ, Gomez MF, Sward K et al. Melatonin restores impaired contractility in aged guinea pig urinary bladder. J Pineal Res 2008; 44: 416-425.

4. Hextall A. Oestrogens and lower urinary tract function. Maturitas 2000; 36 (2): 83-92.

5. Robinson D, Cardozo L. Estrogens and the Lower Urinary Tract Neurourology and Urodynamics 2011; 30: 754-757.

6. Gomez-Pinilla PJ, Pozo MJ, Camello PJ. Aging impairs neurogenic contraction in guinea pig urinary bladder: role of oxidative stress and melatonin. Am J Physiol Regul Integr Comp Physiol 2007; 293: 793-803. 
7. Gourtsoyiannis N, Prassopoulos P, Cavouras D et al. The thickness of the renal parenchyma decreases with age: a CT study of 360 patients. AJR 1990; 155: 541-544.

8. Fliser D, Zeier M, Nowack R et al. Renal functional reserve in healthy elderly subjects. J Am Soc Nephrol 1993; 3: 1371-1377.

9. Fliser D, Franek E, Joest $\mathbf{M}$ et al. Renal function in the elderly: impact of hypertension and cardiac function. Kidney Int 1975; 1: 1196-1204.

10. Fuiano G, Sund S, Mazza G et al. Renal hemodynamic response to maximal vasodilating stimulus in healthy older subjects. Kidney Int 2001; 59: 1052-1058.

11. Berg UB. Differences in decline in GFR with age between males and females. Reference data on clearances of inulin and PAH in potential kidney donors. Nephrol Dial Transplant 2006; 21: 2577-2582.

12. Cusack BJ. Pharmacokinetics in older persons. Am J Geriatr Pharmacother 2004; 2: 274-302.

13. Gourtsoyiannis N, Prassopoulos P, Cavouras D et al. The thickness of the renal parenchyma decreases with age: a CT study of 360 patients. AJR Am J Roentgenol 1990; 155 (3): 541-544.

14. Hoffman RA, Reiter RJ. Rapid pinealectomy in hamsters and othersmall rodents. Anat Rec 1965; 153: 159-121.

15. Waynfort HB, Flecknell PA. Ovariectomy. In: Experimental and Surgical Technique in the Rat. London: Academic Press, 1992: 276-278.

16. Theodorus P, Akerboom M, Sies H. Assay of glutathione, glutathione disulfide and glutathione mixed disulfides in biological samples. Methods Enzymol 1981; 77: 373-383.

17. Buege AJ, Aust SD. Microsomal lipid peroxidation. Methods Enzymol 1978; 52: 302-310.

18. Xiang Li, Dalin He, Linlin Zhang et al. A novel antioxidant agent, astragalosides, prevents shock wave-induced renal oxidative injury in rabbits. Urol Res 2006; 34: 277-282.

19. Reiter RJ. The aging pineal gland and its physiological consequences. Bio Essays.1992; 14: 169-175.

20. Guzzo TJ, Drach GW. Major urologic problems in geriatrics: assessment and management. Ref Med Clin North Am 2011; 95 (1): 253-264.

21. Rechberger T, Skorupski P. The controversies regarding the role of estrogens in urogynecology. Folia Histochemica Et Cytobiologica 2007; 45 (1): $17-21$.

22. Dambros M, Rodrigues PC, Palma CA et al. The effect of ovariectomy and estradiol replacement on collagen and elastic fibers in the bladder of rats. Int Urogynecol J 2003; 14: 108-112.

23. Mundy AR. Structure and function of the lower urinary tract. In Mundy AR (ed): Scientific Basis of Urology. New York: Churchill Livingstone, 1987, pp 48-73.

24. Wein AJ, Levin RM, Barrett DM. Voiding function: relevant anatomy, physiology, and pharmacology. In Gillenwater JY, Grayhack JT, Howards SS, Duckett JD (Eds). Adult and Pediatric Urology 2nd edn. Chicago: Year Book Medical Publishers, 1991: 933-999.

25. Levin RM, Longhurst PA. Pharmacologic basis of bladder and urethral function and dysfunction. In: Raz S (Ed). Female Urology. Philadelphia: WB Saunders Co, 1996: 43-56.

26. Rehfuss A, Schuler C, Maxemous $\mathbf{C}$ et al. Cyclical estrogen and free radical damage to the rabbit urinary bladder. Int Urogynecol J 2010; 21 (4): 489-494.
27. Alpha Dian-Yu Lin, Anita Mannikarottu, Barry A Kogan et al. Estrogen induces angiogenesis of the female rabbit bladder. J Endocrinol 2006; 190: 241-246.

28. Grady D, Brown JS, Vittinghoff $E$ et al. Postmenopausal hormones and incontinence: the Heart and Estrogen/Progestin Replacement Study Obstet Gynecol 2001; 97: 116-120.

29. Goldstein SR, Nanavati N. Adverse events that are associated with the selective estrogen receptor modulator levormeloxifene in an aborted phase III osteoporosis treatment study. Am J Obstet Gynecol 2002; 187: 521-527.

30. Longhurst PA, Eika B, Leggett RE et al. Comparison of urinarybladder function in 6 and 24-month male and female rats. J Urol 1992; 148: $1615-1620$.

31. Lluel P, Palea S, Barras M et al. Functional and morphological modifications of the urinary bladder in aging female rats. Am J Physiol Reg Integr Comp Physiol 2000; 278: 964-972.

32. Kolta MG, Wallace LJ, Gerald MC. Age-related changes in sensitivity of rat urinary bladder to autonomic agents. Mech Ageing Dev 1984; 27 : 183-188.

33. Saito M, Kondo A, Gotoh $\mathbf{M}$ et al. Age-related changes in the response of the rat urinary bladder to neurotransmitters. Neurourol Urodyn 1993; 12: 191-200.

34. Toyoshima A, Onodera S, Yoshinaga $M$ et al. Effects of aging and the autonomic nervous system-related agents on the intravesical pressure of the bladder in situ in female rats. Nippon Yakurigaku Zasshi 1990; 96: 103-115.

35. Lluel P, Deplanne V, Heudes D et al. Age-related changes in urethrovesical coordination in male rats: relationship with bladder instability? Am J Physiol Regul Integr Comp Physiol 2003; 284: 1287-1295.

36. Yoshida M, Homma Y, Inadome A et al. Age-related changes in cholinergic and purinergic neurotransmission in human isolated bladder smooth muscles. Exp Gerontol 2001; 36: 99-109.

37. Onur R, Tasdemir C, Seckin D et al. Combined use of melatonin and terazosin restores bladder contractility in rabbits with partial outlet obstruction. Urology 2008; 72 (2): 439-443.

38. Gomez-Pinilla PJ, Pozo MJ, Camello PJ. Aging impairs neurogenic contraction in guinea pig urinary bladder: role of oxidative stress and melatonin. Am J Physiol Regul Integr Comp Physiol 2007; 293: 793-803.

39. Quiroz Y, Ferrebuz A, Romero F et al. Melatonin ameliorates oxidative stress, inflammation, proteinuria, and progression of renal damage in rats with renal mass reduction. Am J Physiol Renal Physiol 2008; 294: 336-344.

40. Gourtsoyiannis N, Prassopoulos $P$, Cavouras D et al. The thickness of the renal parenchyma decreases with age: a CT study of 360 patients. AJR Am J Roentgenol 1990; 155: 541-544.

41. Rule AD, Amer H, Cornell LD et al. The association between age and nephrosclerosis on renal biopsy among healthy adults Ann Intern Med 2010; 152 (9): 561-567.

42. Glassock RJ. The Aging Kidney. More Pieces to the Puzzle. Mayo Clin Proc 2011; 86 (4): 271-72.

43. Nyengaard JR, Bendtsen TF. Glomerular number and size in relation to age, kidney weight and body surface area in normal man. Anat Rec 1992; 232 (2): 194-201.

44. Pericoa N, Remuzzia G, Benigni A. Aging and the kidney. Curr Opinion Nephrol Hypertens 2011; 20: 312-317.

Received October 12, 2012. Accepted March 8, 2014. 